secondary education. It serves only to confuse the issue and create factitious problems.

When an educationist of Prof. Dent's reputation foresees the emergence of further types of school, the weight of his authority may do something to bring it about. It is to be hoped that he is wrong, since even if the infinite variety of pupils could be fitted into type schools with single-track aims, all 'types' of school could not be made available everywhere to all 'types' of pupil. Rather should we look to the possibility, within a broad conception of education at the secondary stage, of increasing variety within the schools. Instead of multiplying 'types', let us concentrate upon enlarging the capacity and resources of all schools to fit their curricula and methods to the needs of their pupils and thus enable them the better to do their job.

For an eminently readable account of the job the secondary modern schools are actually doing, their difficulties, frustrations and triumphs, we are all indebted to Prof. Dent.

H. RAYMOND KING

\section{FUNDAMENTALS OF SYMBOLIC FORM}

The Philosophy of Symbolic Forms

By Ernst Cassirer. Vol. 1 : Language. Pp. xiv +328. (1953.) 408. net. Vol. 2: Mythical Thought. Pp. xviii + 269. (1955.) 40s, net. Vol. 3 : The Phenomenology of Knowledge. Pp. xvii $+501.68 s$. net. All translated by Ralph Manheim. (New Haven, Conn. : Yale University Press; London : Oxford University Press, 1957.)

TF an attempt is to be made to review what is, in Leffect, the essence of Ernst Cassirer's life and thought the only way is to treat these three volumes together, notwithstanding the fact that they have emerged from the Yale University Press at various times during the past five years. The translator has done adequately (and Cassirer could be extraordinarily subtle at times), while the historical and interpretative introductions enable Prof. Hendel to act as a welcome guide. The author was probably the last great thinker who could range over almost the whole field of human endeavour, and illumine it at every level. For it was nothing less that was required of anyone who set out to show not only the content but also the significance of symbolic form, whether in language, mythical thought or the phenomenology of knowledge. As specialization spreads more and more over the whole complex of man's activities (with the power that it brings to discovery and invention), so less and less likely does it become that a fair estimate can be made of the degree of mental adjustment which has been taking place in our awareness of those ultimate verities which can only be expressed symbolically. One has but to recollect the rapid advance in mathematics which followed the introduction of rational and consistent notations to see how potent a factor 'form' is : and not only visual form, but mental form, too, as it tends to crystallize out in clarity of exposition.

Vol. 1 (on language) is based upon the phenomenology of linguistic form and discusses the problem of language in the history of philosophy, then as a phase of sensuous and intuitive expression. After this comes the relation of language to conceptual thought, while the sphere of judgment is treated in the last chapter. Throughout Cassirer's work runs the thread of Kant's influence (and of the Neo-Kantian school at Marburg), strong at all times, but especially so when the "Critique of Judgment" is regarded as the interpretation of an epoch. Thus, three problems presented themselves as basic : first, the unity of empirical science, secondly, purpose in Nature, and thirdly, the nature of art. It is not difficult to see how paramount for an understanding of form is a system of communication-language-through which alone the search for natural law and man's own contribution can reach axiological stature.

Vol. 2 (on mythical thought) consists of four parts : myth as a form of thought; myth as a form of intuition; myth as a life-form; and the dielectic of mythical consciousmess. (Incidentally, the jacket of this volume carries the title "Mythical Thinking" instead of "Mythical Thought" as on the book itself.)

Of particular interest to the scientist is the discussion of number in relation to the formative period of mathematics. Philolaus (Fragment 11) says that "the nature of number is the cause of recognition, able to give guidance and teaching to every man in what is puzzling and unknown". Translated into psychological terms such as sensation, intuition and feeling, this brings numerical concepts very close to what the Pythagoreans meant by harmony; and centuries later, Husserl, originally a pupil of the great Weierstrass, arrived at his 'structural forms', and through them at something like a calibration factor for the resolving power of the mind.

Vol. 3 (on the phenomenology of knowledge) is essentially a return, in expanded form, to the author's earlier (1910) conception of substance and function. But the emphasis this time is on structure and articulation, in fact a kind of ultimate analysis of a Weltanschauung. Three divisions are clearly discerned, namely, expressive function, representation, and the building up of scientific knowledge. Projected upon this wide intellectual horizon, the earlier volumes, concentrating upon language and myth, are seen at their true value.

To the scientist, the chapters dealing with the object of mathematics, and the system of modern physics will make substantial appeal. In the latter context, it is slightly unfortunate that for Cassirer 'modern physics' necessarily meant the quantum theory of the 1920's-a momentous but somewhat ephemeral phase, and not over-philosophical. What little weakness the translation has comes out here in slight idiomatic mistakes, such as 'ordinal number' for 'atomic number', and 'exponent of refraction' for 'index of refraction'. But a more fundamental matter is the author's strange omission of the Axiomatik of Carathéodory (1908), which must have been known to him when discussing the transition from the crude idea of heat to the modern conception of temperature.

Nevertheless, when all is said and done, these three volumes alone (apart altogether from Cassirer's other papers and books) make an outstanding contribution to epistemology and to the human power of abstraction. It is rather as if "The Golden Bough" had been written in philosophical rather than in historical terms. Scientist and humanist are more closely at one when the theme of knowledge is handled on the grand scale, than they are in the domain of specialized studies. Hand in hand they go, in the quest for an ever more perfect symbolic form, at once rigorous and aesthetically rewarding. F. I. G. RAwLINS 